\title{
Salt Mist Generation Control Unit (SMGCU) for Spa Business
}

\author{
Thanawat Sornnen ${ }^{\mathrm{a}}$, Supanat Nicrotha ${ }^{\mathrm{b}}$ \\ a sornnen@gmail.com, ${ }^{b}$ supanat.nicrotha@gmail.com \\ ${ }^{a}$ Smart Electronics Engineering, Faculty of Industrial Technology, Uttaradit Rajabhat University, Thailand \\ ${ }^{b}$ Machanical Engineer, Independent Reserech, Thailand
}

\begin{abstract}
Halotherapy (HT), originated from Pelotherapy in salt mines, which is a therapeutic culture and is an alternative treatment method in western countries. In Thailand, HT in the simulated salt cave. This method helps to recover in many health issues, such as asthma, respiratory disease, certain skin diseases, and air allergies which are often found today. The problem is ordinary people are difficult to access this therapy owing to the rare service place and the price relatively high. These may be due to the high cost of the built salt cave and the equipment for generating salt mist in spa business.

This research study aimed to design and develop a salt-mist generation control unit (SMGCU) or highpressure salt spray for the HT in the spa business, covering high-performance salt sprayer and inexpensive when compared with the imported equipment. It also designed with a temperature and humidity controller (Temperature and Humidity Controller) that can detect temperature from $\left(-20-80{ }^{\circ} \mathrm{C}\right)$ and humidity range from $0-100 \%$ with displayed on Nextion and mobile phone with application installed. The device developed by using a 3 meters width, 4 meters long and 2.7 meters height spa room.

Based on the performance test of the ultrasonic spray headed and SMGCU in terms of temperature and humidity, the results indicate that the SMGCU can measure temperature and humidity effectively. Additionally, when testing the overall performance of the SMGCU, it founded that it feasibly operated efficiently as the earlier given size and condition's room at the lower fixed cost as well.
\end{abstract}

Keywords-Mist application, atomization, ultrasonic, Halotherapy, Pelotherapy, halo therapeutic, Spa Business

\section{INTRODUCTION}

For background and importance of the problem. The use of saltwater springs in traditional halo therapeutic practices on the evidence of an authentic ethnoscience obtained by human communities, especially in Greek, Latin, and the east of Romania. The analysis of these practices demonstrates their scientific validity from the current biochemical and biophysical perspective. Parts of these practices are taken over by a series of recent halo therapeutic proceedings, with reliable scientific and technological bases [1] and [5]. Many researches explained that HT, derived from pelotherapy in salt mines, is also a drug-free therapeutic method. HT effects vary depending on the therapeutic program and the structure of HT environment. They studied the HT effects of "halotherapy chamber with artificial salt-mine environment" of the National Institute of Rehabilitation, Physical Medicine and Paleoclimatology (INRMFB). The 15 patients who suffer from asthma, 
allergic, chronic bronchitis, and relative symptom, were selected. Then four patients with similar pathologies for the control group, who received in-home drug treatment. After the specific HT, the effects on the inflammatory process were notable. The result data acquired also confirmed the HT effect causing the decrease of body sensitiveness in asthma patients. Several studies on HT have been conducted to suggest that this alternative treatment yields impressive results [5]. Alina and Nora, 2009 [2], performed similar experiments with larger samples in the respiratory disease group, while the control group they took the placebo. The results showed that overall HT treatment resulted in improved clinical status in most patients, but not prevailing significantly. Moreover, the positive dynamics of respiratory flow and a decrease in bronchial resistance were also inspected. Another researcher group experimented among 40 bronchiectasis patients conducted to complete the questionnaire of life quality and spirometry test before and after salt spray for two months. All of these patients, only 20 were evaluated, and the other 20 were excluded for many reasons. The results showed no significant difference $(\mathrm{P}>0.05)$. However, 65\% of the patients were satisfied with HT and asked for repeat treatment. They recommend future studies involving larger sample sizes and longer treatment duration for a better determine HT treatment modality [3]. The recent reports of HT applied through the inhalation of micronized dry salt within a mimic's salt chamber recommend that HT may help the symptoms of Chronic obstructive pulmonary disease (COPD) [4].

Thailand's spa market is ranked 16th in the world and ranked 5th in the Asian region as both Medical Tourism for foreigners and a beauty market for Thai people. Currently, the domestic spa and massage market is worth tens of billions of baht or around $8 \%$ of the business growing now. Although it may not be comparable to "medical services", however, it still has the potential of a market that can grow without the ceiling [6]. Since 2004, the government has urged Thailand to become the medical hub of Asia and promote Thailand as the capital spa of Asia (A world-class spa destination). Although they still had various major problems and obstacles likewise skilled personnel, internal and external factors, marketing at the international standard level, spa innovation and technology, etc. [7]. A complete Himalayan healing salt room is hard to find full 10 points experience, no matter how expensive it is, due to the physical environment of the treatment facility and the therapist lack of empathy and concern of their client [8]

In Thailand, this therapy has been widespread recently, but today it is found that salt cave therapy (HT) in SPA rapidly increase. It is believed that this therapy can help various health issues, for instance, asthma, respiratory disease, certain skin diseases and air allergies. It is claimed that the treatment by entering the salt cave will help flush out toxins. Also, the salt mist can help to reduce the brain waves frequency and reduce stress as well, thereby giving our body a real rest. Salt that is produced to form salt mist particles is called "Pharma Salt" utilized in the pharmaceutical industry. The dry salt used without iodine and tapioca starch has 
antiseptic and anti-inflammatory properties.

The salt spray therapy in spa business has been widespread for at least ten years in Thailand and became more popular nowadays. However, both small and large spas are faced with peripheral equipment problems. Moreover, the service places are not meet the demands of consumers, and the service fee is quite expensive as well. Considering the equipment and materials used to construct the simulated salt cave have to be imported from abroad made the cost is quite high. The required peripherals control unit to operate the spa room is uncertain such as temperature, humidity, and salt spray header controller, including, it is no monitor while servicing the customer. Therefore, it is inconvenient to use and may cause harm to users while providing services, especially for vulnerable customers who require intensive care. So, it is unable to assure customers while receiving the service and unable to facilitate observation of the spa owner as it should be.

Since those reasons, the research team aims to design and develop the proper salt spray generation control for the spa business, which cheaper than imported from abroad. It is also designed to have a temperature and humidity controller that can detect temperature from -20 to $80{ }^{\circ} \mathrm{C}$ and humidity range from $0 \%$ to $100 \%$ with a display of Nextion and mobile phone display including the application developed and installed. The performance testing room will develop with three meters in width, four meters in length and 2.7 meters in height.

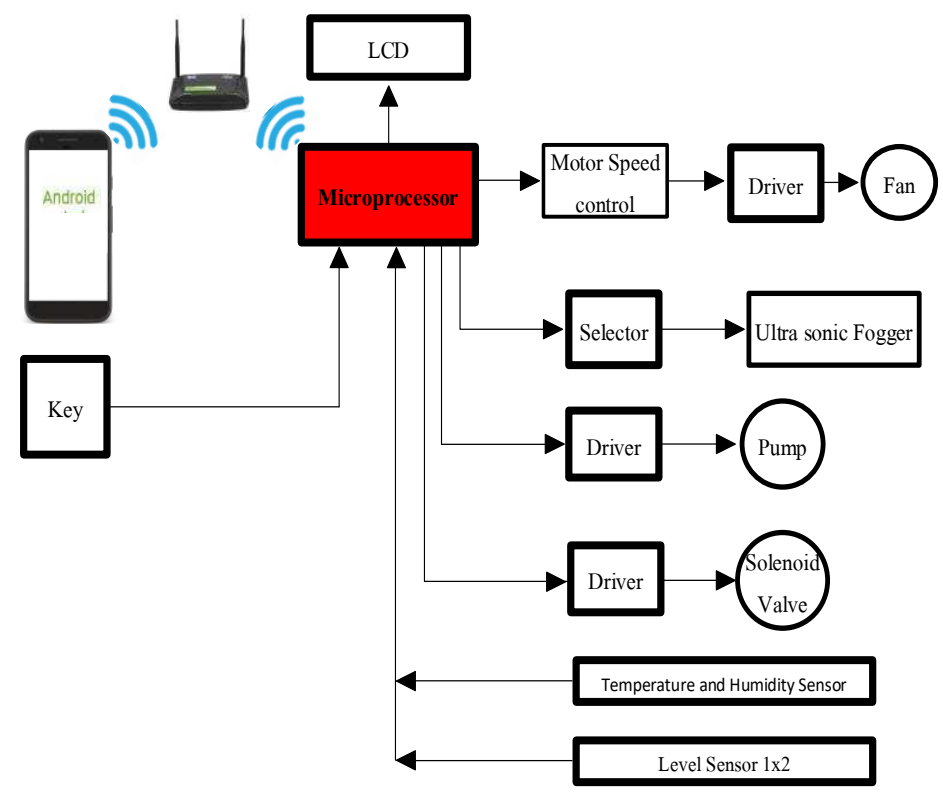

Fig. 1 block diagram of system operation. 


\section{PROPOSED METHODOLOGY}

The methodology of the research will be to design and test the operation of a small automatic machine for creating printed circuit boards according to the following diagram (Figure 1).

\subsection{Ultrasonic Atomization of Liquid}

Ultrasonic is the science of sound waves that transcends the limits of human hearing, frequencies greater than $18 \mathrm{kHz}$ are often considered ultrasonic [9] and [10]. The use of ultrasonic is getting more attention as ultrasonic technology may be a flexible alternative. The process is energy efficient and the environment harmless compared to other methods. In addition, ultrasonic has been applied in multiple fields, including electrical engineering such as ultrasonic transducers, magneto strictive type and piezoelectric type. Also, ultrasound wave has the ability in industries and medical fields like drying, dehydration, welding, extraction, heat transfer, defrosting, oil recovery, atomization, cleaning up, and removal of fine particles [11] and [12]. Ultrasonic atomization is an attractive precise technique to generate mist because of its electrically controllable advantages [13]. Therefore, this study proposes to apply ultrasonic fogger or ultrasonic atomization, which is a notable module operated with other circuit and device to assemble an economy SMGCU, meanwhile, examine the efficiency of SMGCU for supporting small economic spa business. Since the entrepreneur face with the high competition in the market presently.

\subsection{Salt Mist Generation Control Unit System Concept}

An overview of the SMUGS block diagram is shown in Fig. 1, the basic properties and functions of each unit can be described as follows. Key is a manual switch for controlling the system operation to turn onoff systems. Then smartphones handled as a medium for the connection of the microprocessor to command the work of the system to open the application, turn on-off the control system. LCD screen touching display used to display temperature, humidity and control operation system. Microprocessor is a control unit consisting of the Mega2560 UNO ESP 8266 board used to receive commands from smartphones and LCD screens to operate the entire system [14]. Motor Speed Control is a fan speed control unit that used to increase the 3 levels of wind speed. There are 3 drivers in this system, the first driver is a set of distributing voltage to have current according to the usage of the device, its usage is used to distribute the voltage to the device. Fan behaves as an exhaust ventilator use to suck the air in the room and blow the salt mist from the source tank. Another part is ultrasonic fogger uses to be the main equipment for generating salt mist, which is widely used in many fields such as agriculture [17], biomedical [18]. Pump is an equipment uses to suck water from the brine well into the storage tank to be used in the next step. Solenoid valve is a device for preparing water to supply water for the salt spray generator tank which works in a way that turns on - turn off the water when receive command from microprocessor. Temperature and humidity sensor is function to measure temperature and humidity in the room and sends the values to present on the LCD screen. Level sensor is a sensor that serves to detect the Min-Max water level and send the value to microprocessor to command the solenoid valve.

\subsection{Salt Mist Generation Control Unit System Process Design}

The overview processes of the salt mist generation control unit for spa business in the whole model of the salt cave system concerning its sequence of functions are shown in Fig. 2. Starting from Key is a function created for the user to touch or press a button on the machine or the remote control. The SMGCU series will start to execute when the button is pressed according to the command are set. In case we command 
by connecting through a mobile phone, the ESP 8266 will be an intermediary device to operate the machine instead. Later, Switch No. 1 uses to control the operation of the Ultra-Sonic. Switch No. 2 controls the operation of the fan to be able to suck the air from the room follows the default setting. Switch No. 3 controls the operation of the pump that has been set with Solenoid valve to control the on-off of the water supply system that is sent along various pipes. A high-precision temperature and humidity sensor module will operate when the SMGCU has been operating for a period of time. During system operating, the Level sensor detects the water level in the water tank to prevent the occurrence of water levels that are too low to cause the overheating. On the other hand, high water levels may cause flooding. Eventually, it is possible to damage the equipment and the whole system. Finally, the results of the operation and working equipment status are shown on an LED display. Thus, the users able to examine the basic information by them self. Also, the service provider able to monitor and control the system operations to ensure proper operation and safety.

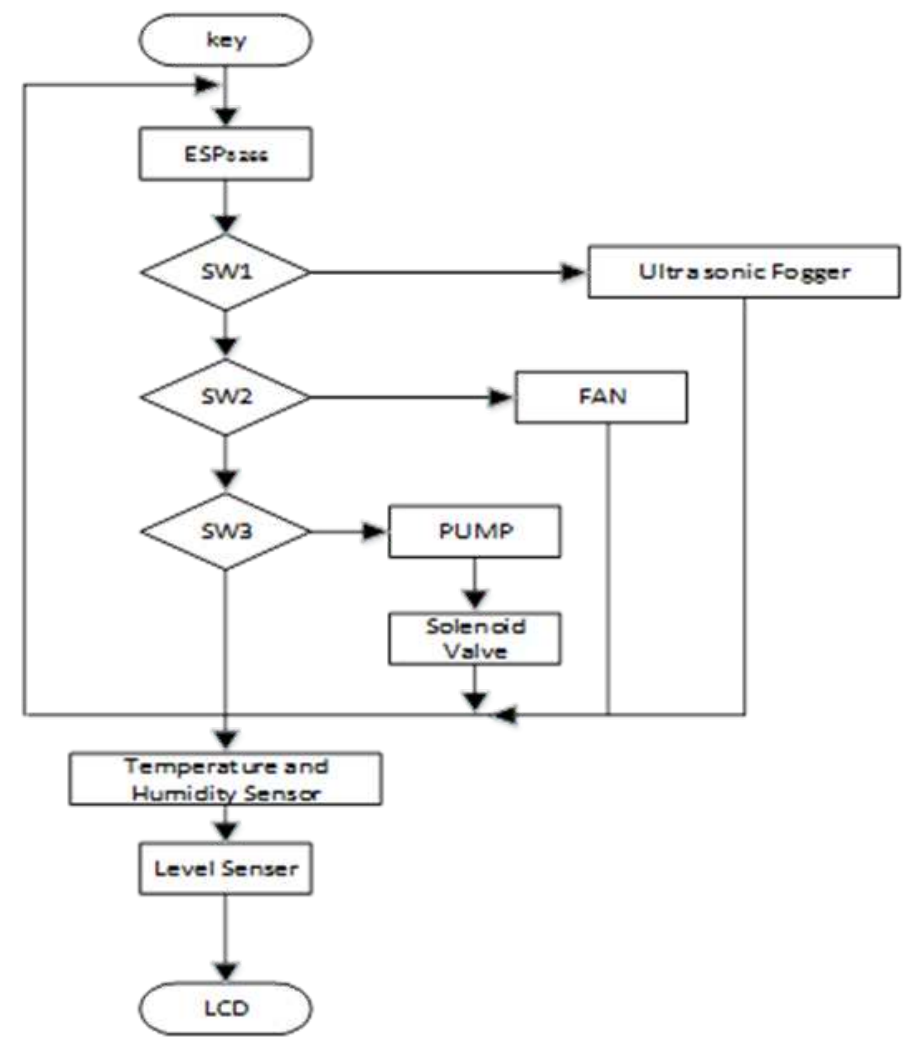

Fig. 2 shows the system process design by a flow chart.

\subsection{Chamber Design for Testing SMGCU Operation Control Systems}

The simulated spa room for testing the SMGCU control unit is designed to be 3 meters in widths, 4 meters in length and 2.7 meters in height. The equipment that will install in the room has four parts: The first part is an air vent designed to let salt mist into the room. The second part is the exhaust fan, used to suck the air in the room to push the mist from the mist generator. The third part is the LCD screen for command and display working status. The fourth section is the bed for the client to rest while taking the salt spray that is released throughout the room to the respiratory system (Fig. 3). 


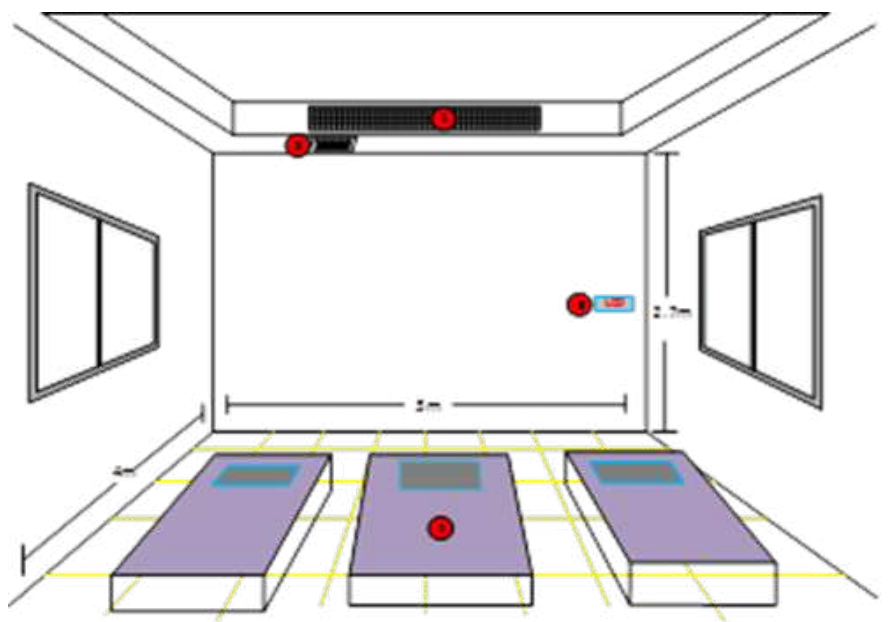

Fig. 3 the chamber design for testing operation of SMGCU control systems.

\subsection{Principle of the Overall System Operation}

The controller part uses the motherboard Arduino Mega 2560 with Wi-Fi NodeMCU ESP 8266 [16], programming the command sequence with the Arduino IDE V.1.8.9 to gather the data from the temperature and humidity sensor for comparison, processing and commanding. The three main tasks are 1) control the speed of the exhaust fan, 12 inches blades, power 20 watts, 2) turn on/off the solenoid valve and water pump, power 180 watts. 3) turn on/off 10 Heads Flogger Ultrasonic, switch to work all 3 of them.

Display and control design work can be done both automatically set up and manually via mobile phone on the Android operating system. That programming through MIT APP Inventor2 and design to store various parameters such as temperature, humidity, a period of time, and timing of each load device to store in the ThingSpeak Web Server which allows you to real-time process, modify, and send notifications [15] and [16].

The principle of the overall SMGCU operation is shown in Fig. 4. The relationship and summary can be described as follows. No. 1) Control cabinet Inside will consist of a complete set of control systems. Devices installed in the control cabinet consist of an LCD screen, a Microprocessor, ESP 8266, and various system drivers. No 2) Pump sucks the brine from the storage tank to deliver it into the tank equipped with Ultra Sonic for use in the process of turning water into mist. No. 3) Solenoid Valve is a normally closed type (N/C), has one entrance and one exit. There is a plunger with a seal on the lower end that opens and closes the fluid orifice when power is applied to or cut off the coil. No. 4) Level Sensor is responsible for detecting the level of solid or liquid objects in both open and closed containers. The knowing position or level of the material inside the container can be converted to other values, such as the volume, weight, usage rate. No. 5) Ultra Sonic Sound waves that are too high in frequency for the human to hear. In general, ultrasonic refers to sound waves with frequencies above $20 \mathrm{kHz}$. They are the device used to turn water into mist [16]. No. 6) Salt fog pipe is used to arrange the salt mist up to the mist vent installed in the room No. 7) an exhaust fan installed for use in sucking the air in the room along the duct to push the fog that has been created, it runs along the salt mist pipeline. No. 8) Air vents serve to emit salt mist to spread throughout the room. No. 9) Brine transport tubes are used to transport the brine from the storage tank to the tank equipped with Ultra Sonic for the conversion from saltwater to salt mist. No. 10) Brine storage tanks are used to hold brine for use in the process of converting from brine to salt mist. 


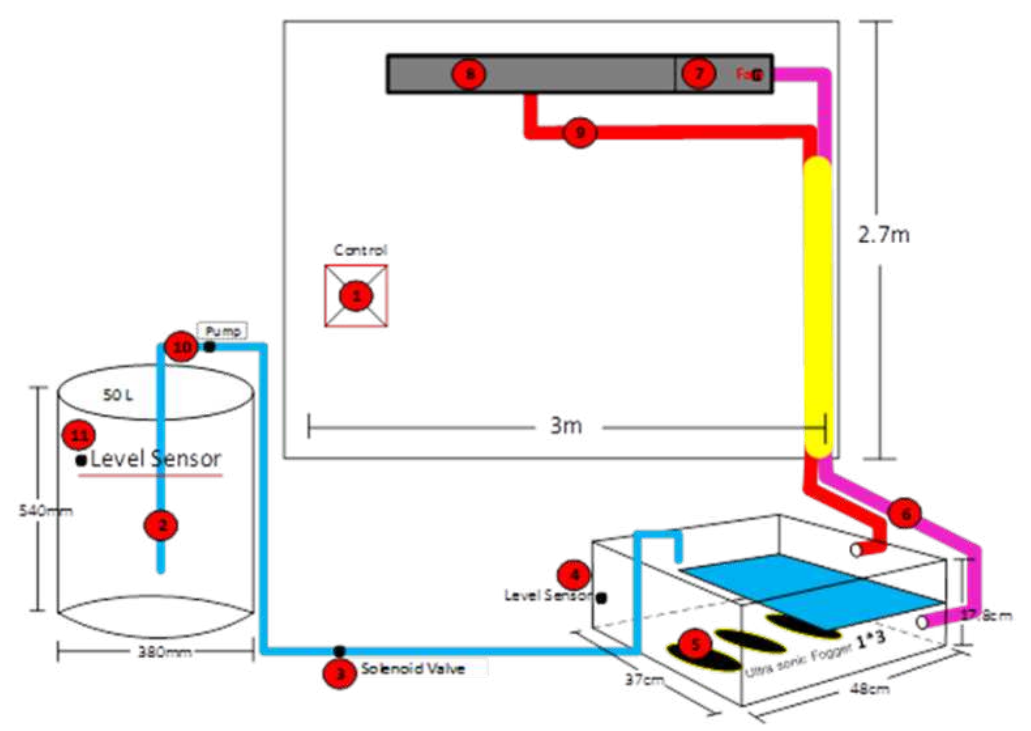

Fig. 4 the principle of overall systems.

\subsection{Principle SMGCU Performance Test}

The study team decided to test the efficacy of SMGCU for the spa business by testing the performance of the ultrasonic head and the operation of the SMGCU. The test will examine the combination turning level between the fan (level 1-3) and ultrasonic (level 1-3), then collected data (temperature, humidity and water level) for each test starting time period increasing every 5 minutes. Study and observing at what level of two combinations (fan and ultrasonic level adjustment) will achieve the most stable operation.

\section{THE EXPERIMENTAL RESULTS}

The results of the salt mist generation control unit (SMGCU) are given into two parts. The first part is a result of is SMGCU, which ready for examination in a simulated performance testing room. Some examples of results are shown in Fig. 5. The following part is a result of SMGCU performance test, the details are illustrated in TABLE I.

\subsection{Salt Mist Generation Control Unit (SMGCU)}

The obtained salt mist generation control unit (SMGCU) after the assembly each module together is ready for examination in a simulated performance testing room. The examples of results are shown in Fig. 5.

\subsection{SMGCU Performance Test}

The results in Table I show that the performance test of SMGCU with fan levelling combined with ultrasonic levelling was tested by adjusting the fan level at level $1-3$ and ultrasonic level 1- 3 at each given time frame. The results data measurement were temperature, humidity, and water level. The temperature could be got a value between 25-30 Celsius, while the humidity could be measured between 77-79\%. 


\begin{tabular}{|c|c|c|c|c|c|}
\hline \multicolumn{2}{|c|}{ Level of } & \multicolumn{4}{|c|}{ Measured Data } \\
\hline Fan & Ultra-Sonic & Time (minute) & Temperature $\left({ }^{\circ} \mathrm{C}\right)$ & Moisture (\%) & $\begin{array}{l}\text { Water Level } \\
\text { (cm) }\end{array}$ \\
\hline \multirow{5}{*}{1} & \multirow{5}{*}{1} & 0 & 29.5 & 78.8 & 7.00 \\
\hline & & 5 & 28.4 & 78.9 & 6.75 \\
\hline & & 10 & 28.6 & 78.6 & 6.50 \\
\hline & & 15 & 28.5 & 78.5 & 6.25 \\
\hline & & 20 & 26 & 78.9 & 5.50 \\
\hline \multirow{5}{*}{1} & \multirow{5}{*}{2} & 0 & 29.5 & 78.8 & 7.00 \\
\hline & & 5 & 28.4 & 78.9 & 6.70 \\
\hline & & 10 & 28.6 & 78.6 & 6.47 \\
\hline & & 15 & 28.5 & 78.5 & 6.37 \\
\hline & & 20 & 26 & 78.9 & 5.60 \\
\hline \multirow{5}{*}{1} & \multirow{5}{*}{3} & 0 & 29.5 & 78.8 & 7.00 \\
\hline & & 5 & 28.4 & 78.9 & 6.00 \\
\hline & & 10 & 28.6 & 78.6 & 5.90 \\
\hline & & 15 & 28.5 & 78.5 & 5.66 \\
\hline & & 20 & 26 & 78.9 & 5.00 \\
\hline \multirow{5}{*}{2} & \multirow{5}{*}{1} & 0 & 29.5 & 78.8 & 7.00 \\
\hline & & 5 & 28.4 & 78.9 & 6.80 \\
\hline & & 10 & 28.6 & 78.6 & 6.77 \\
\hline & & 15 & 28.5 & 78.5 & 6.70 \\
\hline & & 20 & 26 & 78.9 & 6.00 \\
\hline \multirow{5}{*}{2} & \multirow{5}{*}{2} & 0 & 29.5 & 78.8 & 7.00 \\
\hline & & 5 & 28.4 & 78.9 & 6.60 \\
\hline & & 10 & 28.6 & 78.6 & 6.59 \\
\hline & & 15 & 28.5 & 78.5 & 6.23 \\
\hline & & 20 & 26 & 78.9 & 6.10 \\
\hline \multirow{5}{*}{2} & \multirow{5}{*}{3} & 0 & 29.5 & 78.8 & 7.00 \\
\hline & & 5 & 28.4 & 78.9 & 6.69 \\
\hline & & 10 & 28.6 & 78.6 & 6.51 \\
\hline & & 15 & 28.5 & 78.5 & 6.13 \\
\hline & & 20 & 26 & 78.9 & 5.97 \\
\hline \multirow{5}{*}{3} & \multirow{5}{*}{1} & 0 & 29.5 & 78.8 & 7.00 \\
\hline & & 5 & 28.4 & 78.9 & 6.74 \\
\hline & & 10 & 28.6 & 78.6 & 6.65 \\
\hline & & 15 & 28.5 & 78.5 & 5.78 \\
\hline & & 20 & 26 & 78.9 & 4.91 \\
\hline \multirow{5}{*}{3} & \multirow{5}{*}{2} & 0 & 29.5 & 78.8 & 7.00 \\
\hline & & 5 & 28.4 & 78.9 & 6.64 \\
\hline & & 10 & 28.6 & 78.6 & 6.15 \\
\hline & & 15 & 28.5 & 78.5 & 5.51 \\
\hline & & 20 & 26 & 78.9 & 4.80 \\
\hline \multirow{5}{*}{3} & \multirow{5}{*}{3} & 0 & 29.5 & 78.8 & 7.00 \\
\hline & & 5 & 28.4 & 78.9 & 6.54 \\
\hline & & 10 & 28.6 & 78.6 & 6.00 \\
\hline & & 15 & 28.5 & 78.5 & 5.50 \\
\hline & & 20 & 26 & 78.9 & 4.75 \\
\hline
\end{tabular}


During the ultrasonic head operated at levels 1, level 2, and level 3. The brine level in the tank decreased according to the operation of the ultrasonic head, respectively. The brine water level at the starting point is notable start 7 centimeters with ultrasonic level 1 later the water level will drop 0.5 centimeters after every 5 minutes. However, when considering the results of the fan speed adjustment test in conjunction with the ultrasonic head operation. It is seen that the lowest average water level drop and the slowest drop time in the top three are the fan adjustment at level 2 with the ultrasonic level 1 followed by adjusting the fan at level 2 with the ultrasonic level 2 and adjusting the fan at level 2 with the ultrasonic level 3. It can be seen that the increase of the ultrasonic level force the water level decreases significantly faster than the fan level adjustment. Nevertheless, both of these level adjustments do not affect the temperature and humidity levels in every testing time period. The graph are shown in Fig. 6

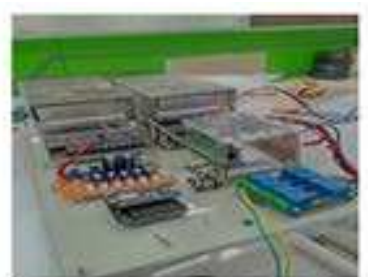

(a) System control unit (SCU).

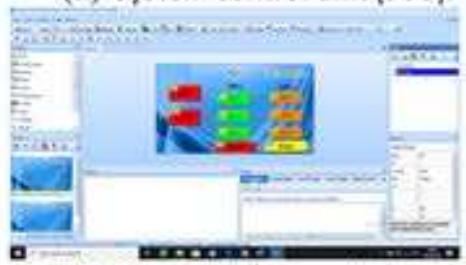

(d) Fan and ultrasonic control screen with Nextion Editor.

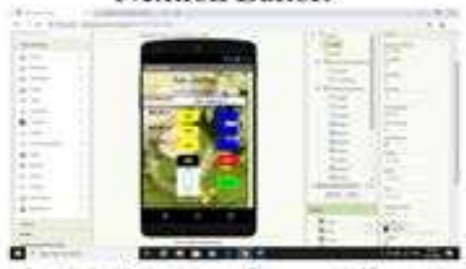

(g) Fan-speed-controller screen design.

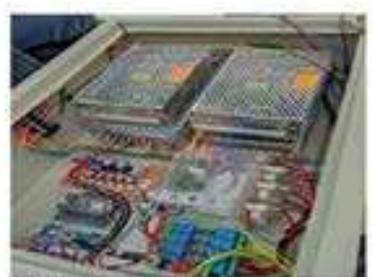

(b) SCU ready for testing.

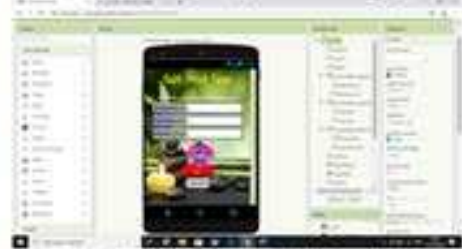

(e) SMGCU mobile phone controlling application design.

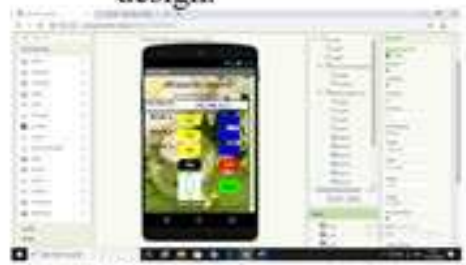

(h) Ultrasonic-control screen design.

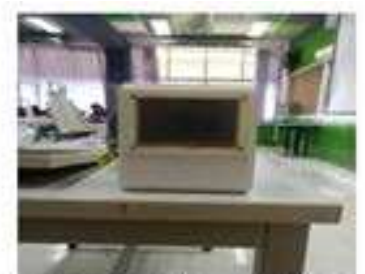

(c) SCU with fan and display.

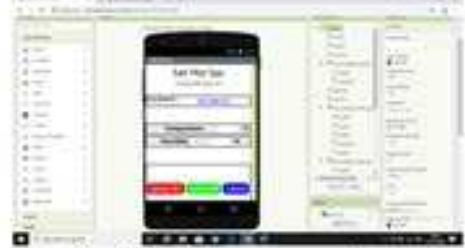

(f) Temperature and humidity display screen.

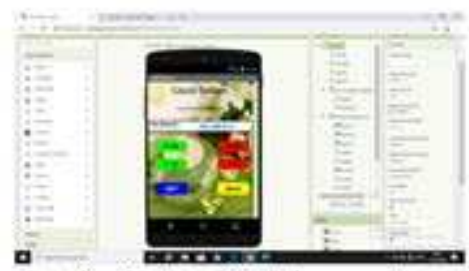

(i) Solenoid Valve and Pump-control screen designed.

Figure 5. SMGCU designed; (a) A system control unit (SCU). (b) SCU ready for testing. (c) SCU with fan and display. (d) Fan and ultrasonic control screen with Nextion Editor. (e) SMGCU mobile phone controlling application design. (f) Temperature and humidity display screen. (g) Fan-speed-controller screen design. (h)

Ultrasonic-control screen design. (i) Solenoid-Valve-control and Pump-control screen designed. 


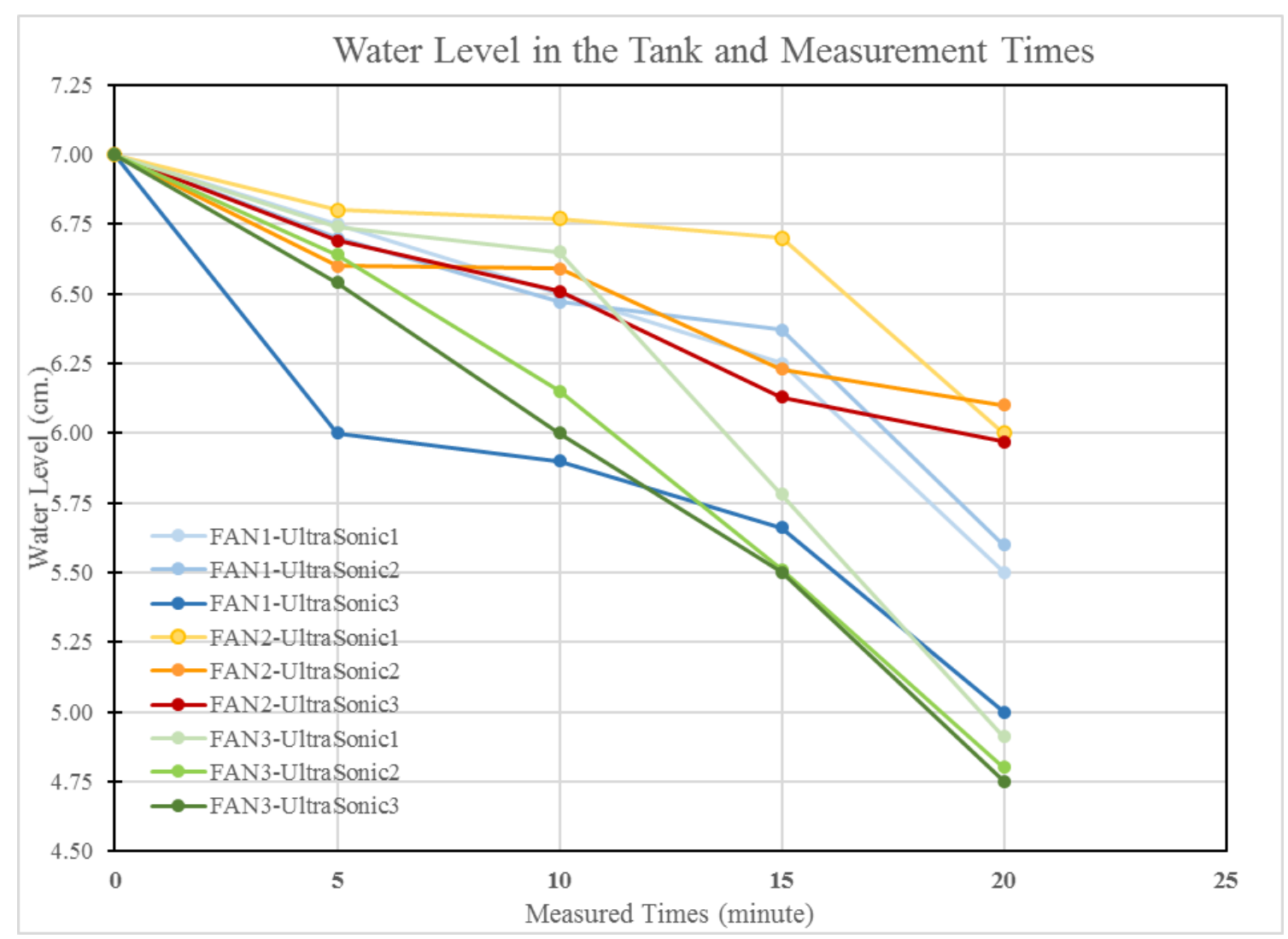

Fig. 6. graph of water level and measurement times, the result from SMGCU performance testing.

\section{CONCLUSIONS}

The salt-mist generation control units (SMGCU) performance examination conducted by evaluating the control ability of the temperature and humidity module in testing rooms. Besides, aiming to measure the efficiency of the ultrasonic and fan by observing water levels in the water tank. The results found that temperature and humidity can be measured and controlled effectively, while the overall performance of the salt-mist generation system testing by adjusting the fan speed level 1-3, together with the ultrasonic power level 1-3. Then, measure the water level in the water tank to observe the effect of both devices when determining the different operation level. The results illustrated that adjusting the mid-level fan (level 2) and ultrasonic at low-level (level 1) yield good results in reduced water consumption and prolonged service time of the salt cave or the salt therapy room as well. In addition, the system can help support users and operators to monitor the salt cave environment or the salt treatment facility. Moreover, an application developed with the friendly user interface, simple designs, easy to learn and to use. Hence, it made the confidence of service recipients and service providers as well. Additionally, this SMGCU partially reducing variable costs in case of adjusting fan and ultrasonic properly function level. Further, it can be reduced the fixed costs of salt cave peripherals that have to be imported. 


\section{DICUSSIONS AND FUTHERWORKS}

The salt mist generation control units for spa business operation testing has some mistakes when the ultrasonic head testing. The position of the ultrasonic head is not placed in a suitable position, resulting in an uneven amount of mist generated during the test. However, it is considered this error does not critically affect the overall performance. After adjusting the proper position, it can be seen that the amount of mist and the mist distribution that has been formed are more consistent. A suggestion for future developments is to add additional functions and sensors to support and enhance the convenience to the user. Also, in developing and constructing salt mist generation control units for spa businesses, the developers need to have principle knowledge and should study the structure and operation of fan and ultrasonic head level control systems. Besides, should know circuit programming and knowledge of electrical and programming, which will enable the creator to develop, design, build a salt mist generation control unit for the spa business to be more effective.

\section{References}

[1] Ion Sandu, Marius Alexianu, Roxana-Gabriela Curcă, Olivier Weller, Constantin Pascu. (2009). HALOTHERAPY: FROM ETHNOSCIENCE TO SCIENTIFIC EXPLANATIONS. in Environmental Engineering and Management Journal. November/December 2009, 8(6): 1331-1338. Available: http://omicron.ch.tuiasi.ro/EEMJ/J. Clerk Maxwell, A Treatise on Electricity and Magnetism, 3rd ed., vol. 2. Oxford: Clarendon, 1892, pp.68-73.

[2] Alina V. Chervinskaya and Nora A. Zilber. Halotherapy for Treatment of Respiratory Diseases. in Journal of Aerosol Medicine. February 2009, 8(3): 221-232. doi:10.1089/jam.1995.8.221.

[3] Rabbani, B., Makki, S. S., Najafizadeh, K., Vishteh, H. R., Shafaghi, S., Karimi, S., \& Mahmoodian, S. (2013). Efficacy of Halotherapy for Improvement of Pulmonary function Tests and Quality of Life of Non-Cystic Fibrosis Bronchiectatic Patients. Tanaffos, $12(2), 22-27$

[4] Rashleigh R, Smith SM, Roberts NJ. A review of halotherapy for chronic obstructive pulmonary disease. in Int J Chron Obstruct Pulmon Dis. 2014;9:239-246. Published 2014 Feb 21. doi:10.2147/COPD.S57511

[5] Lazarescu H, Simionca I, Hoteteu M, Munteanu A, Rizea I, Iliuta A, Dumitrascu D, Dumitrescu E. Surveys on therapeutic effects of "halotherapy chamber with artificial salt-mine environment" on patients with certain chronic allergenic respiratory pathologies and infectious-inflammatory pathologies. J Med Life. 2014;7 Spec No. 2(Spec Iss 2):83-7. PMID: 25870681; PMCID: PMC4391365.

[6] Jarukit Marketeer. Spa-Massage: A Market with Tens of Thousands Main Players and One Other in The Stock Market. Date:03/01/2020. Web site: https://marketeeronline.co/archives/138860

[7] Office of Service and Trade Logistics (DITP), Department of International Trade Promotion (DITP), Ministry of Commerce, Thailand. December 2015. Web site: https://www.ditp.go.th/contents_attach/143532/143532.pdf. (accessed Sep. 18, 2020)๗

[8] Vanniya Sriangura. A spa that satisfies. NEWSPAPER SECTION: LIFE WRITER. PUBLISHED: 16 JUL 2019 AT 04:00. Web site: https://www.bangkokpost.com/life/arts-and-entertainment/1713352/a-spa-that-satisfies. (accessed Sep. 19, 2020)

[9] Cheeke, J.D.N.. Fundamentals and Applications of Ultrasonic Waves. 2002. 10.1201/b12260.

[10] Magesh Jayakumar. Quick Start to Nodemcu (ESP8266) on Arduino IDE. Instructables. Circuits>Arduino . Feb 14th, 2016. [Online]. Available: https://www.instructables.com/Quick-Start-to-Nodemcu-ESP8266-on-Arduino-IDE/

[11] Hans Scharler. ThingSpeak Library for Arduino. Hans on IoT, ThingSpeak, MATLAB, and the Internet of Things. February 12, 2019. [Online]. Available: https://blogs.mathworks.com/iot/2019/02/12/thingspeak-library-for-arduino/

[12] Parvathi, V. IOT based Home Automation using Arduino and NODEMCU. 2018. International Journal for Research in Applied Science and Engineering Technology. 6. 3860-3882. 10.22214/ijraset.2018.4637.

[13] Yu, Kyung-hoon \& Kim, Yong \& Sung, Hyun-Chan. A Study on the Irrigation System of Greenwell Using Ultrasonic Mist Fogger System. 2013. Journal of the Korea Society of Environmental Restoration Technology. 16. 10.13087/kosert.2013.16.6.135.

[14] Ahmed M. Al-Jumaily, Ata Meshkinzar, "On the Development of Focused Ultrasound Liquid Atomizers", Advances in Acoustics and Vibration, vol. 2017, Article ID 7861726, 10 pages, 2017. https://doi.org/10.1155/2017/7861726 